\title{
Factors associated with mental disorders in long-settled war refugees: refugees from the former Yugoslavia in Germany, Italy and the UK
}

Marija Bogic, Dean Ajdukovic, Stephen Bremner, Tanja Franciskovic, Gian Maria Galeazzi, Abdulah Kucukalic, Dusica Lecic-Tosevski, Nexhmedin Morina, Mihajlo Popovski, Matthias Schützwohl, Duolao Wang and Stefan Priebe

\section{Background}

Prevalence rates of mental disorders are frequently increased in long-settled war refugees. However, substantial variation in prevalence rates across studies and countries remain unexplained.

\section{Aims}

To test whether the same sociodemographic characteristics, war experiences and post-migration stressors are associated with mental disorders in similar refugee groups resettled in different countries.

\section{Method}

Mental disorders were assessed in war-affected refugees from the former Yugoslavia in Germany, Italy and the UK. Sociodemographic, war-related and post-migration characteristics were tested for their association with different disorders.

\section{Results}

A total of 854 war refugees were assessed $(\geqslant 255$ per country). Prevalence rates of mental disorders varied substantially across countries. A lower level of education, more traumatic experiences during and after the war, more migration-related stress, a temporary residence permit and not feeling accepted were independently associated with higher rates of mood and anxiety disorders. Mood disorders were also associated with older age, female gender and being unemployed, and anxiety disorders with the absence of combat experience. Higher rates of post-traumatic stress disorder (PTSD) were associated with older age, a lower level of education, more traumatic experiences during and after the war, absence of combat experience, more migrationrelated stress, and a temporary residence permit. Only younger age, male gender and not living with a partner were associated with substance use disorders. The associations did not differ significantly across the countries. War-related factors explained more variance in rates of PTSD, and post-migration factors in the rates of mood, anxiety and substance use disorder.

\section{Conclusions}

Sociodemographic characteristics, war experiences and postmigration stressors are independently associated with mental disorders in long-settled war refugees. The risk factors vary for different disorders, but are consistent across host countries for the same disorders.

\section{Declaration of interest}

None.
Worldwide there are over 15 million refugees, most of whom were displaced because of war and other organised violence. ${ }^{1}$ Large numbers of these refugees remain in recipient countries for many years or even decades, and addressing their health needs can pose a challenge to services. Community studies on long-settled war refugees are rare and have reported raised prevalence rates of mental disorders. ${ }^{2-4}$ Some evidence suggests that a higher level of exposure to both war-related traumatic events and postmigration stressors in the recipient country may be associated with raised rates of mental disorders over many years. ${ }^{3,5}$

Prevalence rates of mental disorders among refugees vary markedly across studies, for example for depression from $2.3^{6}$ to $80 \%{ }^{7}$ and for post-traumatic stress disorder (PTSD) from $4.4^{5}$ to $86 \% .^{7}$ Such variation may partially be explained by methodological differences. ${ }^{8-10}$ It may also reflect substantial differences in sample characteristics and the context of the resettlement, which might interact so that the same sample characteristics are differentially linked to mental disorder rates in different host countries. To test whether the association of refugee characteristics with mental disorders varies across countries, similar groups, preferably from the same background, should be studied in different countries using the same assessment instruments.

In the current study we aimed to: (a) determine which sociodemographic characteristics, war experiences and postmigration factors are associated with mental disorders in war refugees from the same region who have resettled in different countries; (b) determine whether the associations varied across countries; and (c) assess the relative impact of each group of factors on mental disorders and examine the confounding effect of post-migration factors in explaining the relationship between war exposure and mental disorders.

\section{Method}

The study was part of a multicentre survey conducted in five Balkan and three West European countries. The rationale, methods and findings for the Balkan countries have been described in detail elsewhere. ${ }^{11-13}$

\section{Sampling techniques and participants}

A combination of random and non-random sampling approaches was adopted to recruit war-affected refugees from the former Yugoslavia in Germany, Italy and the UK; the three countries with the highest numbers of immigrants in Western Europe in the 1990s. ${ }^{14}$ In Germany and Italy, potential interviewees were identified through resident registers and snowball sampling. Potential participants were identified from data registers based on available data on their surnames, country of origin and year of arrival to the host country. In Germany, registry offices in the 
Berlin and Saxony regions provided data for 22772 potentially eligible participants, from which 5783 participants were randomly selected. In Italy, 4626 potentially eligible participants were identified by the registry offices in the regions Reggio Emilia and Friuli Venezia Giulia. Selected individuals were sent a letter with an invitation to participate in the study and up to two reminders.

In the absence of resident registers in the UK, potential interviewees were contacted through community organisations and snowball sampling. Community organisations mailed invitation letters and one reminder to all their members without revealing individuals' names to the researchers. In total, 1493 potential participants were invited to participate. Of the 11902 letters sent in the three countries, 1226 (778 in Germany, 412 in Italy, 36 in the UK) were returned since the selected individuals could not be located at the given address. In all three countries, the snowball sample was recruited through the first group of respondents. Participants were also recruited at cultural events for refugees.

Participants were included if they were born within the territory of former Yugoslavia; were between 18 and 65 years old; had experienced at least one war-related traumatic event; had experienced the final war-related event at or after 16 years of age; had no severe intellectual disability and no mental impairment due to a brain injury or other organic cause. The traumatic experience was established using a screening list containing 20 stressful events that people may have experienced during wartime. We used the term refugees irrespective of current formal residence status (e.g. citizenship of the recipient country, refugee, asylum seeker).

\section{Procedures and measures}

Face-to-face interviews were carried out between January 2005 and November 2006, and conducted at participants' homes, community organisations or the research centres. Participants' country of origin, age, gender, marital status, educational level, employment and residence status were obtained on a brief structured questionnaire. The history of potentially traumatic experiences before, during and after the war was assessed using an amended version of the 24-item Life Stressor ChecklistRevised. ${ }^{15,16}$ Cumulative scores were calculated for pre-war, war and post-war experiences. For each war event we recorded the year of the occurrence or, in the event of repeated experience, the year of the most stressful occurrence and the level of personal distress experienced at the time of the event (on a five-point Likert scale, ranging from zero, not at all, to four, extremely). Participants were also asked about possible post-migration stressors (separation from family, difficulties in obtaining a work permit or work in own profession, financial difficulties, inadequate accommodation, difficulties in accessing medical care) they may have experienced in the host country resulting in a cumulative score of stressors ranging from zero to six. The perceived level of acceptance by the host country and the command of the language of the host country were assessed using single items (Likert scales, ranging from one, not at all, to five, entirely).

Current mental disorders were established using the Mini International Neuropsychiatric Interview (MINI). ${ }^{17}$ The validity and reliability of the interview has been shown in different cultures ${ }^{17-20}$ and it has been used successfully as a diagnostic tool to identify populations with mental disorders in war-affected populations. ${ }^{21,22}$

Out of the 11 interviewers, 9 were qualified psychologists, 1 a sociologist and 1 an ethnologist. Seven interviewers originated from the former Yugoslavia and four were refugees themselves. All interviewers were bilingual (national language and Bosnian/ Croatian/Serbian or Albanian). The interviewers were trained in the assessment methods. Rating agreement among interviewers was assessed for the MINI in two mock interviews. Item agreement was reached when all interviewers gave the same rating. Among 251 items the average agreement rate was $90.2 \%$. Written informed consent was obtained from all participants prior to the interview. The study was approved by the relevant ethics committees in each country.

\section{Statistical analysis}

Descriptive statistics were used to summarise patient data in each country. For univariate tests of differences between countries, tests and analyses of variance were used. Multivariable logistic regression analyses examined associations between predictor variables and the three types of disorders: mood disorders (major depression, dysthymia, hypomania, mania), anxiety disorders (panic disorder, agoraphobia, social phobia, obsessive-compulsive disorder (OCD), PTSD, generalised anxiety disorder) and substance use disorders (alcohol misuse and dependence, drug misuse and dependence); and specifically PTSD. We selected potential predictor variables that were theoretically meaningful and that have been shown as important in previous research. Variables were entered into the model in three sequential blocks: pre-war factors (sociodemographics, number of pre-war traumatic events); war factors (combat involvement, number of war traumatic events, time since the most traumatic event); and post-war factors (number of post-war traumatic events, postmigration stressors, cohabitation, employment status, feeling accepted by the host country, host language fluency, residence status, country of residence).

Three categorical variables (education level, marital status, employment status) were collapsed into dichotomous ones according to a goodness-of-fit model. The variable 'experienced distress at the time of the most traumatic event during the war' was excluded from multivariable analyses because of its low variance, with approximately $95 \%$ of participants in each country rating the highest option (score 4). Bivariate correlations were assessed using Spearman's correlation coefficient. Country of origin and the length of time since migration were highly correlated with time since the most traumatic war event and excluded from logistic analyses. Multicollinearity among the remaining potential predictor variables was assessed, but none of the variables exceeded a variance inflation factor of five. ${ }^{23}$ For assessing the discriminating ability of the four models predicting anxiety disorders, mood disorders, substance use disorders and PTSD, we calculated receiver operating characteristic (ROC) curves separately for each model. An area under the ROC curve (AUC) of 0.5 indicates no discrimination, and an AUC of 1 perfect discrimination.

To test whether the effects of predictors differed across countries, we tested for interactions between country and each significant predictor variable in multivariable regression analyses. To assess the extent to which pre- and post-migration risk factors explain between-country differences in mental disorders, we fitted logistic models for each of the four outcomes. Using likelihood ratio tests, we first assessed the impact of each pre-migration factor and then of each post-migration factor in the presence of all pre-migration factors. Using logistic and linear regression analyses, sensitivity analyses were performed comparing the likelihood in each country of obtaining basic survival needs, while adjusting for mental health status and age. Finally, we calculated observed and adjusted prevalence rates with standard errors for factors included in the multivariable logistic regression analyses. All factors were dichotomised for this analysis.

For all multiple item scales, sum scores were computed for all participants where $80 \%$ or more of the scale items were answered. Missing data for each item ranged from 0.1 to $7.8 \%$. To examine whether missing data may have biased the results of regression 
analyses, we conducted sensitivity analyses using a multiple imputation method. All analyses were carried out on unweighted data using SPSS 17.0 and Stata 10.1 for Windows.

\section{Results}

A total of 854 participants were interviewed (Germany, 255; Italy, 297; UK, 302). Table 1 summarises the selection processes for each country. Overall, $52.9 \%$ of those people who responded to the invitation letters $(21.2 \%)$ were interviewed. For snowballing, response rates cannot be established. Characteristics of the samples are reported in Table 2.

Participants experienced on average 6.8 different traumatic war events and 2.6 migration stressors. The most frequent warrelated traumatic experiences were 'shelling or bombardment' $(84.9 \%)$, 'lack of shelter' $(64.3 \%)$ and 'being under siege' $(59.3 \%)$. The most frequently experienced migration-related stressors were 'inadequate accommodation' (52.9\%), 'separation from family for a long time' (52.3\%) and 'financial difficulties' (52.2\%). (For details see online Table DS1.) Participants had been in exile on average 9.3 years. Between $41.8 \%$ (in Italy) and $67.9 \%$ (the UK) of refugees in each sample originated from Bosnia and Herzegovina, and each other group of origin represented less than $24 \%$ of the sample.

The three refugee samples differed significantly on all sociodemographic, trauma and migration-related variables, with the exception of gender, level of education, and distress experienced at the time of the most traumatic war event $(P<0.01$ for all between-sample comparisons). Refuges in Italy were younger and had more often been married or cohabiting than samples in Germany or the UK. More than two-thirds of refugees in Italy were employed compared with less than a third of refugees in Germany and the UK. Refugees in Germany reported experiencing the highest number of traumatic events; particularly higher rates were evident for interpersonal assaults such as sexual and nonsexual assaults and torture. They also reported experiencing the highest number of post-migration stressors.

\section{Prevalence of mental disorders}

The prevalence rates of mental disorders for refugees in each country are shown in Table 3 . In the total sample, $54.9 \%$ had at least one of the studied DSM-IV ${ }^{24}$ disorders. Rates of anxiety disorders were $43.7 \%$ (range 30.3-60.7) and of mood disorders $43.4 \%$ (range 30.0-57.4). Substance use disorders, somatisation disorder and psychotic disorders were less frequent across all countries. The prevalence rates of most disorders showed statistically significant variation across countries. Most prevalence rates were highest in Germany and lowest in Italy. The exceptions were higher rates of major depressive episode in the UK and of generalised anxiety disorder in Italy.

\section{Factors associated with mental disorders}

The results of the multivariable hierarchical logistic regression analyses are shown in online Table DS2. Higher rates of mood disorders were associated with female gender, older age, lower education, more traumatic experiences during and after the war, more post-migration stressors experienced, being unemployed, having a temporary residence status and not feeling accepted by the host country.

Higher rates of anxiety disorders were associated with lower education, more traumatic experiences during and after the war, no combat involvement, more post-migration stressors experienced and temporary residence status. Rates of anxiety disorders (but not PTSD) were lower in participants who felt accepted by the host country. Additionally, higher rates of PTSD were associated with older age. A younger age, being male and not living with a partner were associated with higher odds of substance use disorders.

After adjusting for potential confounders, refugees in the UK had the highest odds of mood disorders, whereas refugees in Germany had the highest odds of PTSD and substance use disorders. There were no differences among refugees in the three countries regarding other anxiety disorders.

Results indicated that pre-war factors (Block 1), war factors (Block 2) and post-migration factors (Block 3) each explained a significant amount of variance in the rates of mood disorders $(6.9 \%, 12.2 \%$ and $16.1 \%$ of the variance respectively), anxiety disorders $(5.0 \%, 11.0 \%, 11.5 \%)$ and PTSD $(7.3 \%, 14.2 \%$, $12.8 \%)$. Only pre-war and post-migration factors significantly contributed to variance in the rates of substance use disorders (10.8\% and $20.7 \%)$. The final models therefore explained between 27.5 and $35.2 \%$ of the variance. For mood and anxiety disorders the effects of war exposure remained statistically significant, although somewhat weakened, once post-migration factors were introduced into the model. The effect of time since the most traumatic war event on mood disorders was fully mediated by post-migration factors. Time since the war trauma was the only war factor (and only for mood disorders) for which statistical significance changed once post-migration factors were introduced into the model.

The ROC curves indicated the satisfactory discriminating ability of the models, with an AUC of 0.81 for mood disorders, 0.77 for anxiety disorders, 0.90 for substance use disorders and 0.81 for PTSD.

\section{Stability of associations across the three countries}

Analyses that tested interaction effects between country and each predictor variable and their associations with mental disorders provided no evidence for such effects. Out of the 26 tested interaction effects, only one was statistically significant, as would be expected by chance.

The results of the likelihood ratio tests indicated that postmigration factors fully explained country differences in rates of anxiety disorders. For mood, PTSD and substance use disorders neither pre-migration nor post-migration factors fully explained country differences; however, post-migration factors had the largest impact in reducing the country differences for all three outcomes. None of the individual pre-migration or post-migration risk factors fully explained country differences, although several factors reduced the differences. The number of war experiences partially explained country differences for anxiety disorders and PTSD. Temporary residence and unemployment were the factors with the strongest impact on country differences in rates of mood disorders; temporary residence and post-migration stressors for anxiety disorders and PTSD; and temporary residence status and number of traumatic experiences after the war for substance use disorders. For more detail see online Table DS3.

To further explore country differences, we performed sensitivity analyses comparing the likelihood in each country of basic survival needs being met. After adjusting for age and mental health status, refugees in Germany experienced the highest number of postmigration stressors, including difficulties with employment (obtaining a work permit, work in own profession, and having paid employment) and adequate accommodation, whereas refugees in the UK were the least likely to experience post-migration stressors or not feeling accepted by the host country (Table 4).

\section{Observed and adjusted prevalence rates for factors included in multivariable logistic regression analyses}

The differences in observed and adjusted prevalence rates associated with each of the factors considered in multivariable 


\begin{tabular}{|c|c|c|c|c|c|c|c|}
\hline Sampling design & $\begin{array}{c}\text { Contacted } \\
n\end{array}$ & $\begin{array}{c}\text { Responded } \\
n\end{array}$ & $\begin{array}{c}\text { Not meeting } \\
\text { inclusion criteria, } n\end{array}$ & $\begin{array}{l}\text { Refused to } \\
\text { participate, } n\end{array}$ & $\begin{array}{c}\text { Participants } \\
n\end{array}$ & $\begin{array}{l}\text { Response } \\
\text { rate, \% }{ }^{\mathrm{a}}\end{array}$ & $\begin{array}{l}\text { Participation } \\
\text { rate, \% }\end{array}$ \\
\hline \multicolumn{8}{|l|}{ Total } \\
\hline \multirow{2}{*}{\multicolumn{8}{|c|}{ Random or sampling in community }} \\
\hline & & & & & & & 52.9 \\
\hline Snowballing & NA & NA & NA & NA & 227 & NA & NA \\
\hline \multicolumn{8}{|l|}{ Germany } \\
\hline Random sampling & 5005 & 1324 & 798 & 328 & 198 & 31.5 & 37.6 \\
\hline Snowballing & NA & NA & NA & NA & 57 & NA & NA \\
\hline \multicolumn{8}{|l|}{ Italy } \\
\hline Random sampling & 4214 & 610 & 249 & 106 & 255 & 15.4 & 70.6 \\
\hline Snowballing & NA & NA & NA & NA & 42 & NA & NA \\
\hline \multicolumn{8}{|l|}{ UK } \\
\hline Sampling in community organisations & 1457 & 329 & 31 & 124 & 174 & 23.1 & 58.4 \\
\hline Snowballing & NA & NA & NA & NA & 128 & NA & NA \\
\hline
\end{tabular}

\begin{tabular}{|c|c|c|c|c|c|}
\hline & $\begin{array}{c}\text { Total } \\
(n=854)\end{array}$ & $\begin{array}{l}\text { Germany } \\
(n=255)\end{array}$ & $\begin{array}{c}\text { Italy } \\
(n=297)\end{array}$ & $\begin{array}{c}\text { UK } \\
(n=302)\end{array}$ & $\begin{array}{c}\text { Country } \\
\text { comparison, } P\end{array}$ \\
\hline Females, $n(\%)$ & $438(51.3)$ & $133(52.2)$ & $137(46.1)$ & $168(55.6)$ & 0.063 \\
\hline Age, years: mean (s.d.) & $41.6(10.8)$ & $41.9(10.4)$ & $38.9(10.1)$ & $43.9(11.1)$ & $<0.001$ \\
\hline $\begin{array}{l}\text { Country of origin, } n(\%) \\
\text { Bosnia and Herzegovina } \\
\text { Kosovo } \\
\text { Serbia } \\
\text { Croatia } \\
\text { Macedonia }\end{array}$ & $\begin{array}{l}489(57.3) \\
150(17.6) \\
108(12.6) \\
84(9.8) \\
23(2.7)\end{array}$ & $\begin{aligned} & 160(62.7) \\
& 34(13.3) \\
& 38(14.9) \\
& 19(7.5) \\
& 4(1.6)\end{aligned}$ & $\begin{array}{r}124(41.8) \\
45(15.2) \\
66(22.2) \\
46(15.5) \\
16(5.4)\end{array}$ & $\begin{aligned} & 205(67.9) \\
& 71(23.5) \\
& 4(1.3) \\
& 19(6.3) \\
& 3(1.0)\end{aligned}$ & $<0.001$ \\
\hline $\begin{array}{l}\text { Education level attained, } n \text { (\%) } \\
\text { None or primary education } \\
\text { Secondary school } \\
\text { Vocational/tertiary }\end{array}$ & $\begin{array}{l}188(22.0) \\
354(41.5) \\
312(36.5)\end{array}$ & $\begin{array}{r}59(23.1) \\
113(44.3) \\
83(32.6)\end{array}$ & $\begin{array}{r}61(20.5) \\
130(43.8) \\
106(35.7)\end{array}$ & $\begin{array}{r}68(22.5) \\
111(36.8) \\
123(40.7)\end{array}$ & 0.738 \\
\hline $\begin{array}{l}\text { Marital status, } n(\%) \\
\text { Married/cohabiting } \\
\text { Single } \\
\text { Divorced/separated } \\
\text { Widowed }\end{array}$ & $\begin{array}{l}652(76.3) \\
89(10.4) \\
76(8.9) \\
37(4.3)\end{array}$ & $\begin{array}{l}189(74.1) \\
27(10.6) \\
28(11.0) \\
11(4.3)\end{array}$ & $\begin{array}{r}242(81.5) \\
34(11.4) \\
15(5.1) \\
6(2.0)\end{array}$ & $\begin{aligned} 221 & (73.2) \\
28 & (9.3) \\
33 & (10.9) \\
20 & (6.6)\end{aligned}$ & 0.003 \\
\hline $\begin{array}{l}\text { Employment status, } n \text { (\%) } \\
\text { Employed } \\
\text { Unemployed } \\
\text { Retired } \\
\text { Training/education }\end{array}$ & $\begin{array}{l}351(41.1) \\
438(51.3) \\
31(3.6) \\
34(4.0)\end{array}$ & $\begin{aligned} & 59(23.1) \\
& 167(65.5) \\
& 8(3.1) \\
& 21(8.2) \\
&\end{aligned}$ & $\begin{aligned} 212 & (71.4) \\
76 & (25.6) \\
1 & (0.3) \\
8 & (2.7)\end{aligned}$ & $\begin{array}{r}88(29.1) \\
187(61.9) \\
22(7.3) \\
5(1.7)\end{array}$ & $<0.001$ \\
\hline $\begin{array}{l}\text { Number of traumatic events, mean (s.d.) } \\
\text { Pre-war } \\
\text { War-related } \\
\text { Post-war }\end{array}$ & $\begin{array}{l}1.1(1.3) \\
6.8(3.6) \\
1.1(1.3)\end{array}$ & $\begin{array}{l}1.2(1.3) \\
7.8(3.9) \\
1.5(1.4)\end{array}$ & $\begin{array}{l}0.9(1.2) \\
5.2(2.8) \\
1.0(1.2)\end{array}$ & $\begin{array}{l}1.3(1.4) \\
7.4(3.5) \\
0.9(1.1)\end{array}$ & $\begin{array}{r}0.001 \\
<0.001 \\
<0.001\end{array}$ \\
\hline Time since index ${ }^{a}$ war trauma, years: mean (s.d.) & $10.5(3.1)$ & $11.0(3.0)$ & $9.8(3.3)$ & $10.6(2.9)$ & $<0.001$ \\
\hline Distress at index trauma (0-4), mean (s.d.) & $3.9(0.3)$ & $3.9(0.3)$ & $3.9(0.4)$ & $3.9(0.3)$ & 0.644 \\
\hline Combat involvement, $n(\%)$ & $192(22.5)$ & $59(23.1)$ & $88(29.6)$ & $45(14.9)$ & $<0.001$ \\
\hline Time since migration, years: mean (s.d.) & $9.3(4.4)$ & $10.4(5.3)$ & $7.9(4.1)$ & $9.6(3.4)$ & $<0.001$ \\
\hline Number of post-migration stressors, mean (s.d.) & $2.6(1.6)$ & $3.4(1.5)$ & $2.8(1.4)$ & $1.9(1.4)$ & $<0.001$ \\
\hline Host language fluency, mean (s.d.) & $3.6(1.1)$ & $3.4(1.1)$ & $3.9(1.0)$ & $3.3(1.2)$ & $<0.001$ \\
\hline Feeling accepted by the host country, mean (s.d.) & $3.7(1.0)$ & $3.5(1.0)$ & $3.7(1.0)$ & $3.9(0.9)$ & 0.006 \\
\hline Temporary residence status, $n$ (\%) & $497(58.2)$ & $204(80.0)$ & $202(68.0)$ & $91(30.1)$ & $<0.001$ \\
\hline
\end{tabular}

logistic regressions are shown in online Table DS4 (for observed and adjusted rates by country see online Tables DS5 and DS6).

Observed and adjusted prevalence rates were similar in most cases. The number of potentially traumatic war events was associated with the largest differences in adjusted rates of PTSD and anxiety disorders, whereas being unemployed was associated with the largest differences in adjusted rates of mood disorders. 


\begin{tabular}{|c|c|c|c|c|c|c|}
\hline Disorder & $n$ & $\begin{array}{l}\text { Total } \\
\% \text { (s.e.) }\end{array}$ & $\begin{array}{c}\text { Germany } \\
\% \text { (s.e.) }\end{array}$ & $\begin{array}{l}\text { Italy } \\
\% \text { (s.e.) }\end{array}$ & $\begin{array}{c}\text { UK } \\
\% \text { (s.e.) }\end{array}$ & $\begin{array}{c}\text { Country } \\
\text { comparison, } F\end{array}$ \\
\hline Any mood disorder & 841 & $43.4(1.7)$ & $57.4(3.1)$ & $30.0(2.7)$ & $45.1(2.9)$ & $<0.001$ \\
\hline Major depressive episode & 851 & $34.3(1.6)$ & $36.8(3.0)$ & $25.6(2.5)$ & $40.9(2.8)$ & $<0.001$ \\
\hline Major depressive episode, recurrent & 846 & $15.6(1.3)$ & $11.1(2.0)$ & $14.1(2.0)$ & $20.9(2.4)$ & 0.005 \\
\hline Major depressive episode with melancholic features & 845 & $23.1(1.5)$ & $24.6(2.7)$ & $15.5(2.1)$ & $29.4(2.7)$ & $<0.001$ \\
\hline Dysthymia & 842 & $7.4(0.9)$ & $16.9(2.4)$ & $3.7(1.1)$ & $3.0(1.0)$ & $<0.001$ \\
\hline Hypomanic episode & 850 & $1.5(0.4)$ & $2.7(1.0)$ & $0.7(0.5)$ & $1.3(0.7)$ & 0.13 \\
\hline Manic episode & 850 & $1.9(0.5)$ & $4.3(1.3)$ & $0.3(0.3)$ & $1.3(0.7)$ & 0.002 \\
\hline Any anxiety disorder & 854 & $43.7(1.7)$ & $60.7(3.1)$ & $30.3(2.7)$ & $42.4(2.8)$ & $<0.001$ \\
\hline Panic disorder & 851 & $10.0(1.0)$ & $14.1(2.2)$ & $6.4(1.4)$ & $10.0(1.7)$ & 0.01 \\
\hline Panic disorder with agoraphobia & 852 & $6.7(0.9)$ & $10.6(1.9)$ & $2.7(0.9)$ & $7.3(1.5)$ & 0.001 \\
\hline Agoraphobia without panic disorder & 853 & $8.2(0.9)$ & $12.2(2.1)$ & $2.4(0.9)$ & $10.6(1.8)$ & $<0.001$ \\
\hline Social phobia & 854 & $6.4(0.8)$ & $9.4(1.8)$ & $2.0(0.8)$ & $8.3(1.6)$ & 0.001 \\
\hline Obsessive-compulsive disorder & 854 & $4.8(0.7)$ & $9.4(1.8)$ & $1.0(0.6)$ & $4.9(2.9)$ & $<0.001$ \\
\hline Post-traumatic stress disorder & 854 & $33.1(1.6)$ & $54.9(3.1)$ & $18.9(2.3)$ & $28.8(2.6)$ & $<0.001$ \\
\hline Generalised anxiety disorder & 854 & $8.7(1.0)$ & $4.7(1.3)$ & $14.8(2.1)$ & $6.0(1.4)$ & $<0.001$ \\
\hline Any substance use disorder & 845 & $4.4(0.7)$ & $11.8(2.0)$ & $0.7(0.5)$ & $1.7(0.7)$ & $<0.001$ \\
\hline Alcohol dependence & 854 & $1.8(0.5)$ & $4.7(1.3)$ & $0.3(0.3)$ & $0.7(0.5)$ & $<0.001$ \\
\hline Alcohol misuse & 845 & $4.3(0.9)$ & $1.1(0.3)$ & $1.0(0.8)$ & $1.0(0.6)$ & $<0.001$ \\
\hline Substance dependence & 853 & $1.9(0.5)$ & $6.3(1.5)$ & $0(0)$ & $0(0)$ & $<0.001$ \\
\hline Substance misuse & 853 & $4.2(1.0)$ & $13.4(3.1)$ & $0(0)$ & $0.7(0.5)$ & $<0.001$ \\
\hline Psychotic disorder & 854 & $1.3(0.4)$ & $2.4(1.0)$ & $0.7(0.5)$ & $1.0(0.6)$ & 0.23 \\
\hline Somatisation disorder & 851 & $1.2(0.4)$ & $2.4(0.9)$ & $0.3(0.3)$ & $1.0(0.6)$ & 0.11 \\
\hline Any mental disorder & 853 & $54.9(1.7)$ & $67.8(2.9)$ & $42.1(2.9)$ & $56.6(2.9)$ & $<0.001$ \\
\hline One mental disorder & 854 & $18.6(1.3)$ & $12.2(2.1)$ & $19.9(2.3)$ & $22.5(2.4)$ & 0.004 \\
\hline Two mental disorders & 854 & $16.0(1.3)$ & $18.8(2.5)$ & $12.5(1.9)$ & $17.2(2.2)$ & 0.10 \\
\hline$\geqslant 3$ mental disorders & 854 & $20.3(1.4)$ & $36.9(3.0)$ & $9.8(1.7)$ & $16.6(2.1)$ & $<0.001$ \\
\hline
\end{tabular}

\section{Missing data}

Results from the multiple-imputation regression models were very similar to those using the main non-imputed data-set. The only exception was the variable 'number of post-war traumatic events', which became only marginally statistically non-significant in the PTSD regression model (odds ratio $(\mathrm{OR})=1.12,95 \%$ CI $0.99-1.28, P=0.078$ ).

\section{Discussion}

\section{Main findings}

Although the prevalence rates of mental disorders varied substantially among refugees from the former Yugoslavia in the three countries, sociodemographic characteristics and experiences before, during and after the war showed consistent associations with disorders. Specifically, a lower level of education, more potentially traumatic experiences during and after the war, more migration-related stress, not feeling accepted by the host population, and having a temporary residence status were independently associated with higher rates of both mood and anxiety disorders. Additionally, mood disorders were correlated with female gender, older age and being unemployed. Those with experience of combat had a lower risk of anxiety disorders, whereas older age was associated with PTSD only. Male gender, younger age and not living with a partner were the only factors associated with higher rates of substance use disorders. Postmigration factors accounted for more variance in the rates of mood, anxiety and substance use disorders, whereas war factors did so for PTSD. Except for substance use disorders, both war factors and post-migration stressors directly contributed to the rates of mental disorders. The associations between risk factors and disorders did not vary significantly across countries and did not fully explain the substantial differences in prevalence rates.

\section{Strengths and limitations}

To our knowledge, this is the largest community-based study assessing mental disorders in long-term settled war refugees originating from the same region and now residing in three different recipient countries. The study used identical assessment methods across countries, including face-to-face interviews with a standardised psychiatric diagnostic interview. All interviewers were trained researchers with a relevant professional background, who spoke the mother tongue of the interviewees. Finally, although all participants shared a similar cultural background and had experienced war in the same historical context, further differences among the three samples in relevant risk factors were adjusted for in multivariable analyses. Methodologically, this approach allows a more accurate comparison of risk factors in different contexts than meta-analyses, which commonly consider studies of samples from varying backgrounds in varying contexts.

The study also has four main limitations. First, the combination of registry and snowball sampling, and the variation in the precise recruitment method across countries may have led to nonrepresentative samples. The problem is further compounded by the low response rates, considering all those initially contacted as potentially eligible. The methodological shortcomings in recruiting a fully representative sample of refugees in Western European countries were not a specific fault of this study. They are linked to the non-availability of detailed population data, legislation and research regulations in the participating countries, and shared by most studies of refugee groups. However, the nonrepresentative sampling is more problematic for establishing prevalence rates than for associations between variables, which was the focus of this study. ${ }^{25}$ Second, the retrospective report of traumatic events may have been influenced by recall bias. Substantial, although inconsistent, evidence suggests that people with current post-traumatic stress symptoms tend to report 
more traumatic events, ${ }^{26,27}$ which consequently may inflate the association between reported traumatic experiences and current disorders. Third, the retrospective nature of our study precludes inferences regarding the causal relationships between the existence of current mental disorders and poor socioeconomic situation after migration. For example, unemployment might be a contributing factor in the occurrence or maintenance of a mental disorder or a consequence of the pre-existing mental disorder or both. Finally, the variance explained by each model is limited (27.5-35.2\%), although reasonable for this type of research.

\section{Comparisons with the literature}

The results are consistent with other studies suggesting that war and migration experiences can be associated with mental disorders in long-term settled war refugees. Similarly high rates of mental disorders have previously been reported among long-resettled refugees from regions in the former Yugoslavia ${ }^{28,29}$ and other refugee groups. ${ }^{3,4,30-32}$ Rates of anxiety and mood disorders in this study were higher than those obtained in randomly selected war-affected community samples that remained in five countries of the former Yugoslavia and were assessed using the same methods (rate of anxiety disorders $33.5 \%$ and mood disorders $28.3 \%){ }^{12}$ Although the differences between the two study populations must be interpreted with caution because of the sampling differences, the finding is in line with that of a previous meta-analyses that concluded that refugees tend to have poorer mental health than those who stay in the area of conflict. . $^{8,10,33}$

Our findings suggest a dose-response relationship between war trauma exposure and the likelihood of mood and anxiety disorders several years later, a finding reported in other studies assessing long-term outcomes of war. ${ }^{2-4,30-32,34}$ Low rates of substance use disorders and the absence of a significant link between war experiences and these disorders are consistent with findings among compatriot refugees and those who stayed in the area of conflict ${ }^{12,29}$ as well as other refugee groups. ${ }^{3}$ Combat experience was linked to lower rates of PTSD and other anxiety disorders. It has been argued that soldiers' military training and their belief in protecting country and family help them to cope with traumatic events. ${ }^{35}$

The study identified several post-migration risk factors for mental disorders. In line with previous research, ${ }^{2-4,30,31}$ postmigration trauma exposure and stress, including the feeling of not being accepted in the host country, were positively associated with both mood and anxiety disorders. Despite being resident in a host country for an average of 9 years, more than half of the studied refugees still had a temporary residency status, which was associated with higher rates of both mood and anxiety disorders. The present study adds to the evidence ${ }^{36,37}$ that prolonged unstable residential status and living under a continuous threat of repatriation may contribute to the persistence of mental disorders in refugees. Unlike mood and anxiety disorders, substance use disorders were associated only with non-war-related risk factors, i.e. male gender, younger age and not living with a partner, findings that are also consistent with other research. ${ }^{3,12}$

It has been argued that post-migration factors may mediate ${ }^{38}$ or supersed ${ }^{39}$ the impact of war trauma on mental disorders. However, our findings indicate an independent association of war trauma exposure with mood and anxiety disorders, which remained significant, although weakened, after post-migration factors were included in the analysis. Stressful social and material conditions in resettlement independently predicted mental health status as well as, or better than, actual exposure to war trauma. These findings echo those of two recent studies. ${ }^{40,41}$ They add 
to the debate as to whether trauma-focused therapies or approaches focusing on ongoing psychosocial stressors are more appropriate to understand and address the mental health needs of war refugees. ${ }^{42}$ According to the findings of our study, both war exposure and stressful social and material conditions in resettlement should be considered.

\section{Differences and similarities between countries}

Prevalence rates varied substantially among the refugees in the three countries, with the highest rates for refugees in Germany and the lowest for those in Italy. Some of these differences are explained by differences in the characteristics of the incoming refugees, such as previous war experiences. However, even after taking refugee characteristics into account, some differences are associated with post-migration risk factors such as employment, residence status and other post-migration stressors that refugees experience. Although some of these differences diminish when the identified risk factors are adjusted for in multivariable analyses, most remain significant.

Several selection processes are likely to have influenced the differences among samples in different countries. They include the motivation to seek refuge in a specific country, the chance to reach and be accepted in the given country, the decision and ability to stay in the host country for more than 5 years, and finally the factors influencing participation in the study. In Germany, the policy to grant a residency permit only to refugees who are in treatment for post-traumatic stress may explain the high rates of mental disorders in this sample. ${ }^{43}$ The same selection process may also explain low employment rates - those with poorer mental health are less likely to be employed. ${ }^{44}$ Conversely, in Italy a residency permit was granted only to refugees who were employed or had an employed immediate family member ${ }^{45}$ resulting in high employment rates and low rates of mental disorders. In the UK, asylum seekers were prevented from entering the labour market after arrival, and thus dependent on welfare provisions. This in turn runs the risk of fixing the refugee in the role of passive victim and fostering dependency on public assistance in the long term, which may explain the high unemployment rates in this sample.

Circumstances for refugees in Germany stand out as rather different from the refugees in Italy and the UK. Refugees in Germany reported much higher rates of interpersonal assaults, including torture. This difference in the profile of traumatic events may further explain higher rates of mental disorders in this country given that exposure to interpersonal assaults may particularly increase the risk for onset and persistence of mental disorders. ${ }^{10,11}$ Even after adjusting for mental health status, post-migration circumstances were much poorer for refugees in Germany, with the large majority failing to obtain a work permit, an employment appropriate to their skill level and adequate accommodation. Unemployment may further compromise the chances of integration, prevent recovery from existing mental disorders and contribute to the onset of new disorders, in particular depression. ${ }^{6}$ The depression rate was particularly high in refugees in the UK, who had a similarly high unemployment rate as refugees in Germany.

Several international studies have shown that prevalence rates of mental disorders are usually lower in the general population in Italy compared with other European countries. ${ }^{46}$ The cultural and socioeconomic reasons for the low rates remain poorly understood, but may also have an impact on the mental disorders in the refugees.

Factors associated with each type of mental disorder were the same across the three host countries, indicating that predictive associations were not dependent on the country of refuge and were consistently identified despite a substantial variation of prevalence rates.

\section{Implications}

War refugees appear to have high rates of mental disorders even several years after resettlement and probably require substantial levels of support from health and social services. Prevalence rates varied substantially among countries and most of this variation remained unexplained in this study. The country differences may be linked to specific resettlement policies, and refugees in less socioeconomically inclusive recipient countries might have more mental disorders. Future research may explore the impact of the recipient society further with more specific measures of social and economic inclusion. One may conclude that findings on prevalence rates, even for a very similar group of war refugees, are context specific and need to be established for each country separately. Once the differences in the prevalence rates among countries are taken into account, the same factors may be considered to estimate the risk for mental disorders. Results of research on risk factors in a similar group of refugees appear to be generalisable, at least across countries that share some cultural and political features, as Germany, Italy and the UK do. Policies for the provision of health and social care in each country can target similar risk groups.

Policies addressing the mental health needs of war refugees may have to include both trauma-focused interventions and support to improve the current social and material situation of the refugees. ${ }^{41}$

\section{Funding}

This study was funded by a grant from the European Commission (contract number INCO-CT-2004-509175).

\section{Acknowledgements}

We thank the CONNECT study group - Violeta Arnaudova, Jelena Blazevic, Arlinda Cherga, Niccolo Colombini, Paolo Curci, Kristina Dionisio, Dubravka Salcic-Dizdarevic, Senadin Fadilpasic, Sanja Filipovic, Martina Flego, Ardiana Idrizi, Ljubica Ivanovic, Radojka Kraljevic, Daut Krasniqi, Alma Dzubur Kulenovic, Almir Kulla, Sanja Macura, Bekrije Maxhuni, Alma Bravo-Mehmedbasic, Tijana Miladinovic, Lendita Morina, Katerina Naumova, Giovanni Neri, Bravo-Mehmedbasic, Tijana Miladinovic, Lendita Morina, Katerina Naumova, Giovanni Neri,
Bojana Pejuskovic, Sandra Penic, Katja Pöhnitzsch, Linda Rajhvajn, Gyltene Retkoceri, Masa Romagnoli, Besa Shala, Violeta Stare, Elma Sukaj, Zdravko Tovilovic, Anne-Kathryn Will, Ksenija Yeeles and Blerim Zeqiri who helped us with the project at various stages.

Marija Bogic, BSc, Unit for Social and Community Psychiatry, Barts and The London School of Medicine and Dentistry, Queen Mary University of London, UK:

Dean Ajdukovic, PhD, Faculty of Philosophy, University of Zagreb, Croatia;

Stephen Bremner, PhD, Centre for Primary Care and Public Health, Barts and The London School of Medicine and Dentistry, Queen Mary University of London, UK;

Tanja Franciskovic, MD, PhD, School of Medicine, University of Rijeka, Croatia; Gian Maria Galeazzi, MD, PhD, School of Medicine, University of Modena and Reggio Emilia, Italy; Abdulah Kucukalic, MD, PhD, School of Medicine, University of Sarajevo, Bosnia and Herzegovina; Dusica Lecic-Tosevski, MD, PhD, Belgrade University School of Medicine, Serbia; Nexhmedin Morina, PhD, Department of Clinical Psychology, University of Amsterdam, The Netherlands; Mihajlo Popovski,

PhD, Faculty of Philosophy, University of Skopje, FYR Macedonia; Matthias

PhD, Faculty of Philosophy, University of Skopje, FYR Macedonia; Matthias
Schützwohl, PhD, Department of Psychiatry and Psychotherapy, University of

Technology, Dresden, Germany; Duolao Wang, PhD, Department of Epidemiology and Population Health, London School of Hygiene and Tropical Medicine, University of London, UK; Stefan Priebe, FRCPsych, Unit for Social and Community Psychiatry, Barts and The London School of Medicine and Dentistry, Queen Mary University of London, UK

Correspondence: Marija Bogic, Academic Unit, Newham Centre for Mental Health, Cherry Tree Way, London E5 8NS, UK. Email: m.bogic@qmul.ac.uk

First received 13 Apr 2011, final revision 8 Jul 2011, accepted 15 Sep 2011 


\section{References}

1 United Nations High Commissioner for Refugees. 2009 Global Trends: Refugees, Asylum-seekers, Returnees, Internally Displaced and Stateless Persons. UNHCR, 2010 (http://www.unhcr.hk/files/unhcr/news/ 2009\%20Global\%20Trends.pdf).

2 Mollica RF, McInnes K, Poole C, Tor S. Dose-effect relationships of trauma to symptoms of depression and post-traumatic stress disorder among Cambodian survivors of mass violence. Br J Psychiatry 1998; 173: 482-8.

3 Marshall GN, Schell TL, Elliott MN, Berthold SM, Chun CA. Mental health of Cambodian refugees 2 decades after resettlement in the United States. JAMA 2005; 294: 571-9.

4 Gerritsen A, Bramsen I, Deville W, van Willigen LHM, Hovens JE, van der Ploeg HM. Physical and mental health of Afghan, Iranian and Somali asylum seekers and refugees living in the Netherlands. Soc Psychiatry Psychiatr Epidemiol 2006; 41: 18-26.

5 Steel Z, Silove D, Phan T, Bauman A. Long-term effect of psychological trauma on the mental health of Vietnamese refugees resettled in Australia: a population-based study. Lancet 2002; 360: 1056-62.

6 Beiser M, Hou F. Language acquisition, unemployment and depressive disorder among Southeast Asian refugees: a 10-year study. Soc Sci Med 2001; 53: 1321-34.

7 Carlson EB, Rosser-Hogan R. Cross-cultural response to trauma: a study of traumatic experiences and posttraumatic symptoms in Cambodian refugees. J Trauma Stress 1994; 7: 43-58.

8 Porter M, Haslam N. Predisplacement and postdisplacement factors associated with mental health of refugees and internally displaced persons: a meta-analysis. JAMA 2005; 294: 602-12.

9 Fazel M, Wheeler J, Danesh J. Prevalence of serious mental disorder in 7000 refugees resettled in Western countries: a systematic review. Lancet 2005; 365: 1309-14.

10 Steel Z, Chey T, Silove D, Marnane C, Bryant RA, van Ommeren M. Association of torture and other potentially traumatic events with mental health outcomes among populations exposed to mass conflict and displacement: a systematic review and meta-analysis. JAMA 2009; 302: 537-49.

11 Priebe S, Bogic M, Ashcroft R, Franciskovic T, Galeazzi GM, Kucukalic A, et al. Experience of human rights violations and subsequent mental disorders: a study following the war in the Balkans. Soc Sci Med 2010; 71: 2170-7.

12 Priebe S, Bogic M, Ajdukovic D, Franciskovic T, Galeazzi GM, Kucukalic A, et al. Mental disorders following war in the Balkans - a community based study on long-term outcomes in five countries. Arch Gen Psychiatry 2010; 67: $518-28$.

13 Morina N, Böhme HF, Ajdukovic D, Bogic M, Franciskovic T, Galeazzi GM, et al. The structure of posttraumatic stress symptoms in survivors of war: a confirmatory factor analysis of the Impact of Event Scale - Revised. J Anxiety Disord 2010; 24: 606-11.

14 Eurostat. Population Statistics - Data 1960-2003. Office for Official Publications of the European Communities, 2004 (http://epp.eurostat.ec europa.eu/cache/ITY_OFFPUB/KS-BP-04-001/EN/KS-BP-04-001-EN.PDF).

15 Wolfe J, Kimerling R. Gender issues in the assessment of posttraumatic stress disorder. In Assessing Psychological Trauma and PTSD (eds J Wilson, TM Keane): 192-238. Guilford, 1997.

16 Priebe S, Matanov A, Jankovic Gavrilovic J, McCrone P, Ljubotina D, Knezevic $G$, et al. Consequences of untreated posttraumatic stress disorder following war in former Yugoslavia: morbidity, subjective quality of life, and care costs. Croat Med J 2009; 50: 465-75.

17 Sheehan DV, Lecrubier $\mathrm{Y}$, Sheehan $\mathrm{KH}$, Amorim $\mathrm{P}$, Janavs J, Weiller $\mathrm{E}$, et al. The Mini International Neuropsychiatric Interview (M.I.N.I.): the development and validation of a structured diagnostic psychiatric interview for DSM-IV and ICD-10. J Clin Psychiatry 1998; 59 (suppl 20): s22-33.

18 Rossi A, Alberio R, Porta A, Sandri M, Tansella M, Amaddeo F. The reliability of the Mini-International Neuropsychiatric Interview-Italian Version. J Clin Psychopharmacol 2004; 24: 561-3.

19 Kadri N, Agoub M, El Gnaoui S, Alami KM, Hergueta T, Moussaoui D. Moroccan colloquial Arabic version of the Mini International Neuropsychiatric Interview (MINI): qualitative and quantitative validation. Eur Psychiatry 2005; 20: $193-5$.

20 Otsubo T, Tanaka K, Koda R, Shinoda J, Sano N, Tanaka S, et al. Reliability and validity of Japanese version of the Mini-International Neuropsychiatric Interview. Psychiatry Clin Neurosci 2005; 59: 517-26.
21 Naeem F, Mufti KA, Ayub M, Haroon A, Saifi F, Qureshi SM, et al. Psychiatric morbidity among Afghan refugees in Peshawar, Pakistan. J Ayub Med Coll Abbottabad 2005; 17: 23-5.

22 Morina N, Ford JD. Complex sequeulae of psychological trauma among Kosovar civilian war victims. Int J SOC Psychiatry 2008; 54: 425-36.

23 Stine RA. Graphical interpretation of variance inflation factors. Am Stat 1995; 49: 53-6.

24 American Psychiatric Association. Diagnostic and Statistical Manual of Mental Disorders (4th edn) (DSM-IV). APA, 1994

25 Etter JF, Perneger TV. Snowball sampling by mail: application to a survey of smokers in the general population. Int J Epidemiol 2000; 29: 43-8.

26 Southwick SM, Morgan CA, Nicolaou AL, Charney DS. Consistency of memory for combat-related traumatic events in veterans of Operation Desert Storm. Am J Psychiatry 1997; 154: 173-7.

27 Mollica RF, Caridad KR, Massagli MP. Longitudinal study of posttraumatic stress disorder, depression, and changes in traumatic memories over time in Bosnian refugees. J Nerv Ment Dis 2007; 195: 572-9.

28 Mollica RF, Sarajlic N, Chernoff M, Lavelle J, Sarajlic IV, Massagli MP. Longitudinal study of psychiatric symptoms, disability, mortality, and emigration among Bosnian refugees. JAMA 2001; 286: 546-54.

29 von Lersner $U$, Wiens $U$, Elbert T, Neuner F. Mental health of returnees: refugees in Germany prior to their state-sponsored repatriation. BMC Int Health Hum Rights 2008; 8: 8.

30 Nicholson BL. The influence of pre-emigration and post-emigration stressors on mental health: a study of Southeast Asian refugees. Soc Work Res 1997; 21: 19-31.

31 Blair RG. Risk factors associated with PTSD and major depression among Cambodian refugees in Utah. Health Soc Work 2000; 25: 23-30.

32 Sabin MP, Cardozo BL, Nackerud LP, Kaiser RM, Varese L. Factors associated with poor mental health among Guatemalan refugees living in Mexico 20 years after civil conflict. JAMA 2003; 290: 635-42.

33 Porter M, Haslam N. Forced displacement in Yugoslavia: a meta-analysis of psychological consequences and their moderators. J Trauma Stress 2001; 14: 817-34.

34 Chung RC, Kagawa-Singer M. Predictors of psychological distress among Southeast Asian refugees. Soc Sci Med 1993; 36: 631-9.

35 Basoglu M, Mineka S, Paker M, Aker T, Livanou M, Gok S. Psychological preparedness for trauma as a protective factor in survivors of torture. Psychol Med 1997; 27: 1421-33.

36 Momartin S, Steel Z, Coello M, Aroche J, Silove DM, Brooks R. A comparison of the mental health of refugees with temporary versus permanent visas. Med J Aust 2006; 185: 357-61

37 Steel Z, Silove D, Brooks R, Momartin S, Alzuhairi B, Susljik I. Impact of immigration detention and temporary protection on the mental health of refugees. Br J Psychiatry 2006; 188: 58-64.

38 Steel Z, Silove D, Bird K, McGorry P, Mohan P. Pathways from war trauma to posttraumatic stress symptoms amongst Tamil asylum seekers, refugees and immigrants. J Trauma Stress 1999; 12: 421-35.

39 Gorst-Unsworth C, Goldenberg E. Psychological sequeulae of torture and organized violence suffered by refugees from Iraq. Trauma-related factors compared with social factors in exile. Br J Psychiatry 1998; 172: 90-4.

40 Rasmussen A, Nguyen L, Wilkinson J, Vundla S, Raghavan S, Miller KE, et al. Rates and impact of trauma and current stressors among Darfuri refugees in Eastern Chad. Am J Orthopsychiatry 2010; 80: 227-36.

41 Fernando GA, Miller KE, Berger DE. Growing pains: the impact of disasterrelated and daily stressors on the psychological and psychosocial functioning of youth in Sri Lanka. Child Dev 2010; 81: 1192-210.

42 Miller KE, Rasmussen A. War exposure, daily stressors, and mental health in conflict and post-conflict settings: bridging the divide between traumafocused and psychosocial frameworks. Soc Sci Med 2010; 70: 7-16.

43 Kühne P, Rüßler H. Die Lebensverhältnisse der Flüchtlinge in Deutschland. [The living conditions of refugees in Germany.] Campus-Verlag, 2000.

44 Sturm R, Gresenz CR, Pacula RL, Wells KB. Labor force participation by persons with mental illness. Psychiatr Serv 1999; 50: 1407.

45 Cozzoli P. I rifugiati politici. [Political refugees.] Instrumenta 2000; 4: 835-3.

46 de Girolamo G, Polidori G, Morosini P, Scarpino V, Reda V, Serra G, et al. Prevalence of common mental disorders in Italy: results from the European Study of the Epidemiology of Mental Disorders (ESEMeD). Soc Psychiatry Psychiatr Epidemiol 2006; 41: 853-61. 